\title{
BMJ Open Evaluation of demands, usage and unmet needs for emergency care in Yaoundé, Cameroon: a cross-sectional study
}

\author{
Young Sun Ro, ${ }^{1}$ Sang Do Shin, ${ }^{2}$ Joongsik Jeong, ${ }^{3,4}$ Min Jung Kim, ${ }^{1}$ \\ Young Hee Jung, ${ }^{1}$ Joseph Kamgno, ${ }^{5}$ Etoundi Mballa Georges Alain, ${ }^{6}$ \\ Bonaventure Hollong ${ }^{7}$
}

To cite: Ro YS, Shin SD, Jeong $\mathrm{J}$, et al. Evaluation of demands, usage and unmet needs for emergency care in Yaoundé, Cameroon: a crosssectional study. BMJ Open 2017;7:e014573.

doi:10.1136/bmjopen-2016014573

- Prepublication history for this paper is available online. To view these files please visit the journal online (http://dx.doi.org/10.1136/ bmjopen-2016-014573).

Received 4 October 2016 Revised 8 December 2016 Accepted 6 January 2017

CrossMark

For numbered affiliations see end of article.

Correspondence to Dr Sang Do Shin; shinsangdo@gmail.com

\section{ABSTRACT}

Objectives: To assess the burden of emergent illnesses and emergency care system usage by Yaoundé residents and to evaluate unmet needs for emergency care and associated barriers.

Design: A cross-sectional study using a communitybased survey.

Setting: Yaoundé, Cameroon.

Participants: All residents living in Yaoundé were selected as the target population to investigate the needs and usage of emergency care in Yaoundé. 14 households in every health area (47 in total) were selected using 2-stage sampling.

Primary outcome measures: Unmet needs for emergency care.

Results: Among the 3201 participants from 619 households who completed the survey, 1113 (34.8\%) with median age of 22 experienced 1 or more emergency conditions in the previous year. Respondents who experienced emergency conditions used emergency units $(7.0 \%)$, outpatient clinics $(46.5 \%)$ or hospitalisation $(13.0 \%)$, and in overall, $68.8 \%$ of them reported unmet needs for emergency care. The primary reasons for not seeking healthcare were economic issues $(37.2 \%)$ and use of complementary medicine $(22.2 \%)$. Young age (adjusted OR (95\% Cl) 1.80 (1.23 to 2.62)), rental housing (1.50 (1.11 to 2.03)) and moderate household income (0.60 (0.36 to 0.99$))$ were associated with unmet needs for emergency care.

Conclusions: Residents of Yaoundé had a high demand for emergency care, and high unmet needs were observed due to low emergency care usage. Development of a cost-effective, universal emergency care system is urgently needed in Cameroon.

\section{INTRODUCTION}

A significant burden of diseases observed in low-income and middle-income countries (LMIC), including sub-Saharan Africa, is attributable to time-sensitive illnesses and

\section{Strengths and limitations of this study}

- Providing universal emergency care to all regardless of socioeconomic status remains a challenge all over the world. However, the low-income and middle-income countries have very limited information on usage and cost of emergency care services.

- This study demonstrated the high incidence of emergency conditions, low usage and high unmet needs for emergency care in Yaoundé, Cameroon, using community-based survey and face-to-face interviews which provide a comprehensive, population-based estimation of demands for an emergency care system.

- The limitation was that we could not estimate the prevalence of demands, usage and unmet needs for emergency care for the whole target population. Although we used two-stage sampling methods to obtain a representative sample of residents in Yaoundé, the vital statistics at the community level were not available.

acute injuries. ${ }^{1-5}$ However, shortage of emergency care facilities and limited capacity add to preventable morbidity and mortality from acute medical or surgical conditions, imposing a burden for emergency care. ${ }^{126}$ There is increasing evidence for an emergency care system in LMIC as a public health strategy for secondary disease prevention as well as addressing the rapidly growing global burden of time-sensitive illnesses and acute injuries. ${ }^{1-3} 7^{7} 8$ The limited availability of resources, however, is still a barrier to the development and implementation of emergency care systems in LMIC.

An emergency care system is an integral part of the healthcare system that represents the frontline of care and an entry point to healthcare facilities. ${ }^{7}$ The purpose of an effective emergency care system is to provide 
universal emergency care to all regardless of socioeconomic status, to stabilise patients who have a lifethreatening illness or injury, and to reduce consequences of preventable mortality, morbidity and disability. ${ }^{1} 499$ All components of an emergency care system have a lasting impact on population health through integrated support for providing emergency care in the community, during transportation and on arrival at receiving facilities. ${ }^{1} 4910$

While the need for emergency care systems has been emphasised, whether emergency care is equally accessible and reliable to the public in sub-Saharan Africa is unknown. ${ }^{5}{ }^{11}$ In accordance with the three core functions of public health, assessment in prehospital and hospital emergency care one should proceed to provide evidences for policy development and assurance of an emergency care system. ${ }^{4}$ Comprehensive assessment of emergency care needs as well as the availability and quality of emergency care will help understand the extent of unmet needs and plan strategies for developing an emergency care system that incorporates costeffectiveness and socioeconomic considerations.

Monitoring and assessment of the demands and unmet needs for emergency care in Yaoundé would serve as a critical basis for developing a targeted emergency care system in Cameroon. However, the demands, usage and unmet needs for an emergency care system in Cameroon have not yet been assessed, and whether or not there are any barriers to accessing emergency care needs to be identified. The objectives of this study are to assess the burden of emergency illnesses and the demands and usage of emergency care by Yaoundé residents and to evaluate unmet needs within the past 1 year and barriers to emergency care access.

\section{METHODS}

\section{Study design and setting}

This is a cross-sectional study using a community survey data performed in Yaoundé, Cameroon. The Republic of Cameroon is a LMIC located in Central Africa. Cameroon has an estimated population of 22.7 million with life expectancy of 55 years and median age of 18 years in 2014. Population growth rate was $2.6 \%$ and birth rate was 36.6 births per 1000 population. Gross national income per capita around $\$ 1360$ using the Atlas method ( $\$ 2400$, purchasing power parity) and literacy rate was $75 \% .{ }^{12}$ Health expenditures were $4.1 \%$ of gross domestic product (GDP) and immunisation coverage rates among 1-year olds were $80-90 \%$. Age-standardised mortality rates by communicable, noncommunicable and injuries were 769, 675 and 106 per 100000 population, respectively, and HIV/AIDS prevalence rate was $4.5 \% .{ }^{13}$ Subscriptions to landline phone and mobile phone were 4 and 71 per 100 inhabitants and internet users were $21 \%$ of the total population. ${ }^{14}$

The capital city of Cameroon, Yaoundé with a population of $\sim 3.0$ million, includes six health districts (Biyem
Assi, Cité Verte, Djoungolo, Efoulan, Nkolbisson and Nkoldongo) with each health district providing coverage for between 4 and 12 health areas and their constituting communities. ${ }^{14}$ There are currently 6 teaching hospitals, 6 district hospitals and 47 healthcare centres in Yaoundé. Among the five tertiary care centres, four have emergency units and three receive trauma patients. ${ }^{15}$

The country uses the fee-for-service model to pay for medical care, and patients are required to supply necessary medications and supplies to the hospital after direct purchase in pharmacies. Health insurance programmes are poorly structured, and between 2010 and 2014, 94.2\% of private expenditure on health was out-of-pocket expenditure. ${ }^{12}$ The WHO estimates the density of physicians and nurses as 0.8 and 4.4 per 10000 population, respectively. ${ }^{13}$ Medical and nursing students graduate with little specialty training in emergency care due to lack of comprehensive curriculum in emergency medicine, which leaves emergency care providers difficult to evaluate and manage a broad spectrum of emergency conditions. For prehospital emergency care, the French Service d'Aide Médicale Urgente (SAMU) system is available in Yaoundé. ${ }^{16}$ The SAMU is a prepaid system; however, usage of SAMU is very limited due to high cost, poor equipment and lack of trained healthcare professionals. There were a total of 11 functioning ambulances (2 for SAMU and 9 for hospitals) in Yaoundé and no working emergency phone number for prehospital emergency care.

\section{Study population}

All residents living in Yaoundé were the target population for the purpose of investigating the demands and usage of emergency care in Yaoundé. Study population included those who agreed to participate in this study and lived in Yaoundé during the study period. Incomplete household data and those with unknown information of age and gender were excluded.

\section{Sample size and sampling}

The target sample size was 658 households. Sample size was extrapolated using the expanded programme on immunisation cluster sampling method, which was established and initiated in 1974 by WHO to rapidly assess vaccination coverage and needs in developing countries. ${ }^{17}$ A population parameter of 0.5 and design effect of 6 were used to allow for the design structure of this study, resulting in a required sample size of 576 . We hypothesised a $10 \%$ non-response rate and aimed to select 14 households in every health area (47 in total), totalling 658 households.

Two-stage sampling was used to obtain a representative sample of the target population. First stage sampling was conducted to randomly select a town from each of the 47 health areas as a sampling cluster. From every selected community, 14 households were then selected as sampling units via convenience sampling. 


\section{Study protocols}

Twenty surveyors composed of medical or nursing students were recruited from the Yaoundé 1 Medical School and Nursing School. All surveyors received a mandatory 2-day training prior to the survey. The surveyors were informed on the methodology of the survey as well as detailed procedures and instructions on how to conduct the survey.

Using a structured survey form and variable dictionary, face-to-face interviews were conducted from 11 to 15 December 2014 in the six health districts of Yaoundé. Twenty surveyors were divided into 10 teams of two, and each team was instructed to conduct face-to-face interviews in 14-21 households a day during the 5-day period. Surveyors were instructed to call the research team for consultation if they had any concerns or questions during the survey via their mobile phone.

We blocked the geographical survey town on the basis of street boarder on a commercial map. Recruitment of participants into the study living in the geographical survey area was based on a door-to-door approach at residential properties. At the centre of each sampled community, surveyors randomly selected a direction, and the most proximal house that lies in the chosen direction was selected to participate in the survey. From the first house, subsequent houses were selected by visiting the next available house. From each household selected, an adult over 19 years of age was asked to participate. There was no particular method of selecting a respondent; any adult in a family was able to participate regardless of his or her sociodemographic characteristics. Selected member of the household was informed of the study, and only those who provided written or oral consent was chosen as a respondent. One respondent per household was selected to provide information on behalf of the entire household and family members. Surveyors filled out the survey forms on behalf of the respondent. On completion, respondents were offered a gift (toothpaste or soap) for their time. The survey continued until at least 14 households were surveyed in each town.

To ensure the quality of data, all survey forms were collected by the research team at the end of the day and were subsequently entered into Microsoft Excel (Microsoft Corporation, Seattle, Washington, USA) on the following day after the survey by independent data entry contractors. Surveyors were immediately informed if the survey forms were incomplete or inaccurately filled in. For enhanced quality control, the research team randomly selected one surveyed community each day and revisited the houses to make sure the data were accurately collected.

\section{Data collection and measurements}

A structured survey form was designed to collect quantitative data. The questionnaire was composed of four sections: demographic information; socioeconomic information; healthcare usage for emergency conditions in the previous year; and unmet needs for severe and emergency conditions in the previous year.

Demographic information included age, gender, number of family members, and address, and socioeconomic information included language, education, occupation, household income, health insurance and residential information. For healthcare usage for emergency conditions, healthcare was defined as visits to outpatient clinic, emergency unit or hospitalisation. Emergency condition was defined by participant's judgement expressing that he or she had a condition severe enough to seek healthcare including immediate emergency care use. Conditions were categorised as neurological, cardiovascular, surgical, psychiatric, paediatric, obstetric, ophthalmological, trauma, haemorrhage, infection, intoxication/metabolic disorder, allergies, foreign body and other. In terms of unmet needs for emergency condition management, the primary reasons for not seeking healthcare were classified into seven categories: accessibility (long distance to hospital, or lack of transportation or hospital); affordability (economic issue); social and familial disapproval (family and/or friend's advice); distrust in hospital (do not think hospital care is effective); complementary medicine (selfmedication, home care or traditional medicine); severity (personal judgement that the condition was not severe enough to visit hospital); and others.

A total of 34 questions were asked in closed-ended or open-ended questions. A pilot test was conducted that surveyors were given a survey guide with explanations and notes on every question. Based on the pilot test, it was anticipated that the survey will take $\sim 10-15 \mathrm{~min}$ to complete. Both the survey form and survey guide were initially developed in English and were subsequently translated into French by a translator in Cameroon.

\section{Main outcomes}

The primary end point of this study was demand of emergency care. The demand was defined as subjective conditions, in which participants felt as an emergency condition to be managed at once or within a short time period, which could be several hours or several days. The secondary outcome was unmet needs for emergency care; unmet needs were defined as non-usage of healthcare including emergency care services despite an individual's demand for emergency care due to emergency conditions. The tertiary end point was reasons for not seeking healthcare.

\section{Statistical analysis}

Descriptive analysis was performed to compare the distributions of demographic factors by demand (emergency conditions) and unmet needs, and statistically significant differences between the groups were analysed via Pearson's $\chi^{2}$ test (categorical variables) and Wilcoxon rank-sum test (continuous variables). $\mathrm{p}$ Values were calculated based on a two-sided significance level of 0.05 . 
Proportions of the reasons for not seeking healthcare were calculated.

Among those who experienced emergency conditions in the previous year, individual factors associated with unmet needs for emergency care were examined by calculating adjusted ORs (AORs) and 95\% CIs using a multivariable logistic regression model. Stepwise selection methods were used with models that contain age and gender. All statistical analyses were performed using SAS software, V.9.4 (SAS institute, Cary, North Carolina, USA).

\section{Ethical statements}

Administrative authorisation was obtained from the regional delegate of Yaoundé and Division of Operation Research in Health at the Cameroon Ministry of Health (No. D30-168/L/MINISTANTE/SG/DROS/DTLC).

\section{RESULTS}

\section{Demographic findings of respondents}

Among 667 households approached for the survey, 619 households (response rate 92.8\%) with 3201 participants completed the surveys for all household members excluding those with unknown age or gender $(n=26$; figure 1).

Of the 3201 survey respondents enrolled, 1113 (34.8\%) experienced one or more emergency conditions in the previous year. Among survey respondents who experienced emergency conditions in the previous year, $498(44.8 \%)$ had household income of $<$ XAF25 $000 \quad(\sim$ US $\$ 40)$ per week. Only $2.7 \%$ of survey respondents had health insurance and respondents who experienced emergency conditions were less likely to have health insurance ( $1.4 \%$ vs $3.4 \%, \mathrm{p}<0.01$; table 1$)$.

Of 1113 survey respondents who experienced emergency conditions in the previous year, $766(68.8 \%)$ reported experiencing unmet needs for emergency care. Respondents who lived close to a teaching hospital or those who lived far from a district hospital were less likely to have unmet needs (both of $\mathrm{p}<0.01$ ). The proportion of respondents with household income of $<$ XAF15 000 was higher in the group with unmet needs

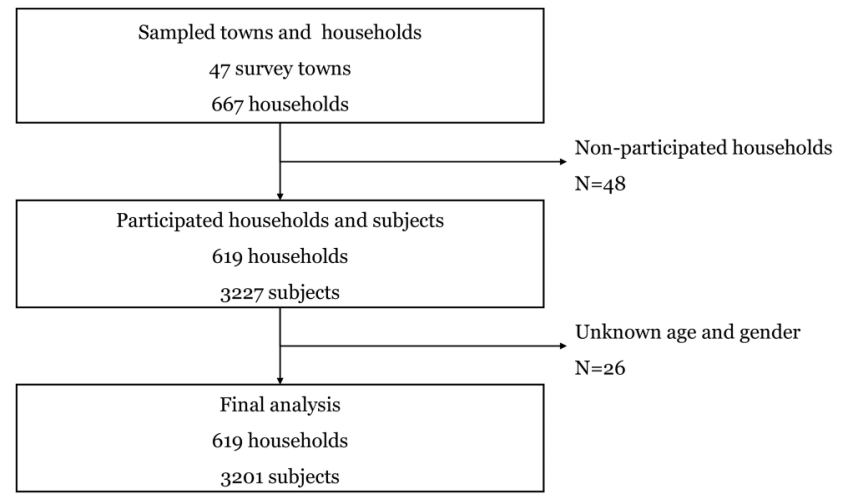

Figure 1 Survey participants. than those without it (14.2\% vs $12.1 \%)$. Among the respondents who experienced emergency conditions, $7.0 \%$ used emergency units, $46.5 \%$ visited outpatient clinics and $13.0 \%$ had been hospitalised. More respondents without unmet needs for emergency care used primary clinics, emergency units and hospitalisation one or more times than those who experienced unmet needs $(66.8 \%$ vs $36.6 \%, 14.7 \%$ vs $3.6 \%$ and $24.5 \%$ vs $7.7 \%$, respectively; table 2 ).

\section{Reasons for having unmet needs for emergency medical services}

Among all emergency conditions, neurological condition was the most frequent, followed by intoxication/ metabolic disorder, cardiovascular emergency and infection. The proportion of unmet needs was highest in patients with psychiatric emergency $(88.9 \%)$ followed by allergies $(75.5 \%)$ and haemorrhage $(67.3 \%)$; in contrast, lowest proportions of patients reported unmet needs if had foreign body (33.3\%), obstetric emergency $(37.3 \%)$ and trauma $(44.4 \%)$. For those with unmet needs, the primary reasons for not seeking healthcare were economic issue $(37.2 \%)$; use of complementary medicine $(22.2 \%)$; personal judgement that condition was not severe enough to visit hospital $(8.7 \%)$; limited accessibility to hospital $(5.7 \%)$; and social and family disapproval $(4.6 \%$; table 3$)$.

\section{Multivariable logistic analysis for unmet needs}

For respondents who experienced emergency conditions in the previous year, young age (18-35 vs $36-55$ years old, AOR $(95 \% \mathrm{CI})=1.80$ (1.23 to 2.62) ) and rental housing (vs owned, AOR (95\% CI) $=1.50$ (1.11 to 2.03)) were associated with unmet needs for emergency care. Those who lived far from a teaching hospital or close to a district hospital were also more likely to have unmet needs for emergency care. Those with moderate household income were less likely to experience unmet needs in the previous year (XAF25 001-XAF50 000/week vs XAF0-XAF10 000/week, AOR (95\% CI $)=0.60 \quad(0.36$ to $0.99)$; table 4).

\section{DISCUSSION}

We observed a high incidence of emergency conditions, low usage and high unmet needs for emergency care in Yaoundé, Cameroon, using a community-based survey which provides a comprehensive, population-based estimation of demands for an emergency care system. Affordability and use of complementary medicine were primary factors for not seeking healthcare, and young age and low socioeconomic position were associated with unmet needs for emergency care. Assessment of demands, usage and unmet needs for emergency care is a basic step for developing an effective emergency care system and reducing preventable mortality and morbidity from time-sensitive illnesses and acute injuries. The demands and unmet needs identified in this study 
Table 1 Demographics of survey respondents by emergency conditions in the last year

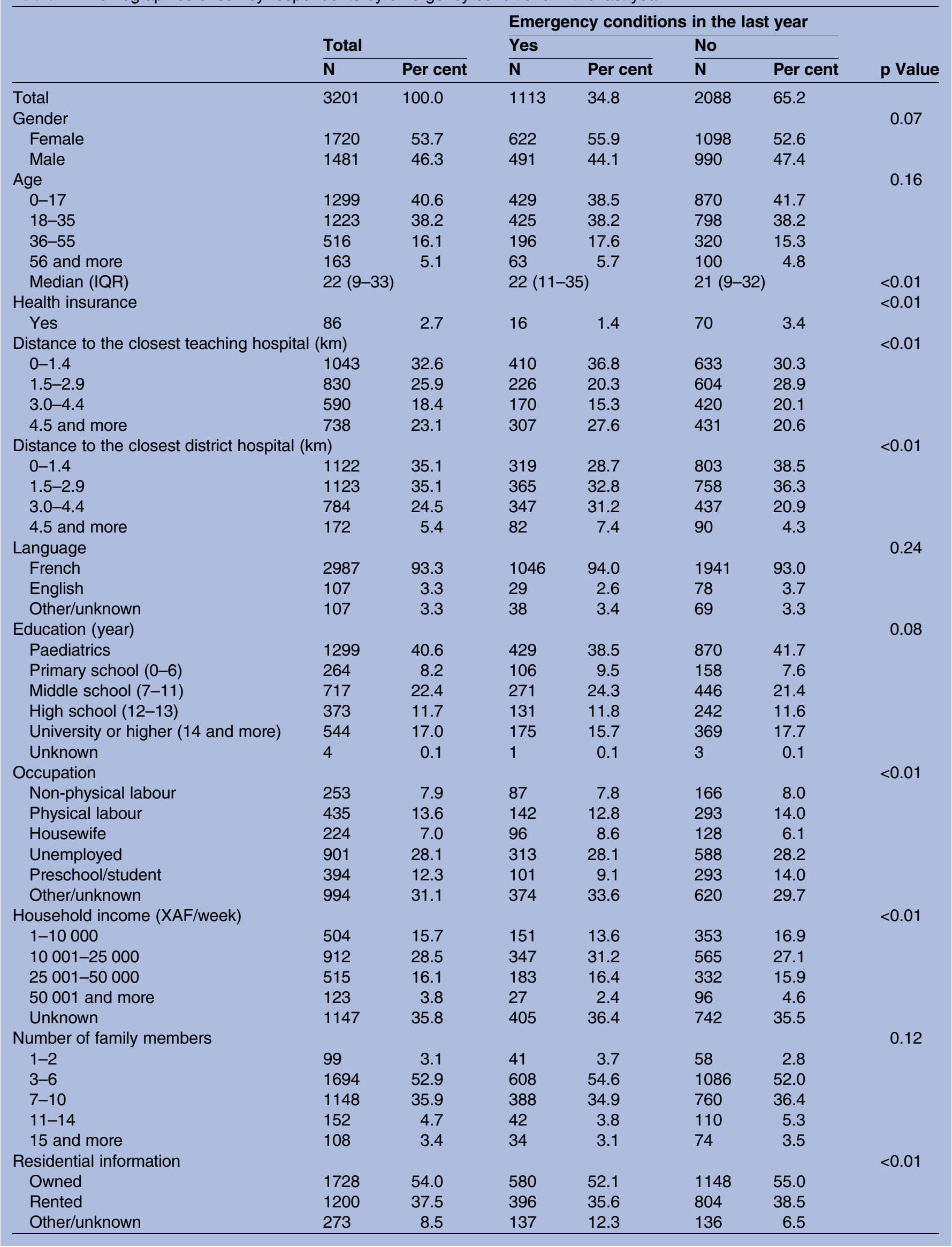


Table 2 Demographics by unmet needs in respondents who had emergency conditions in the last year

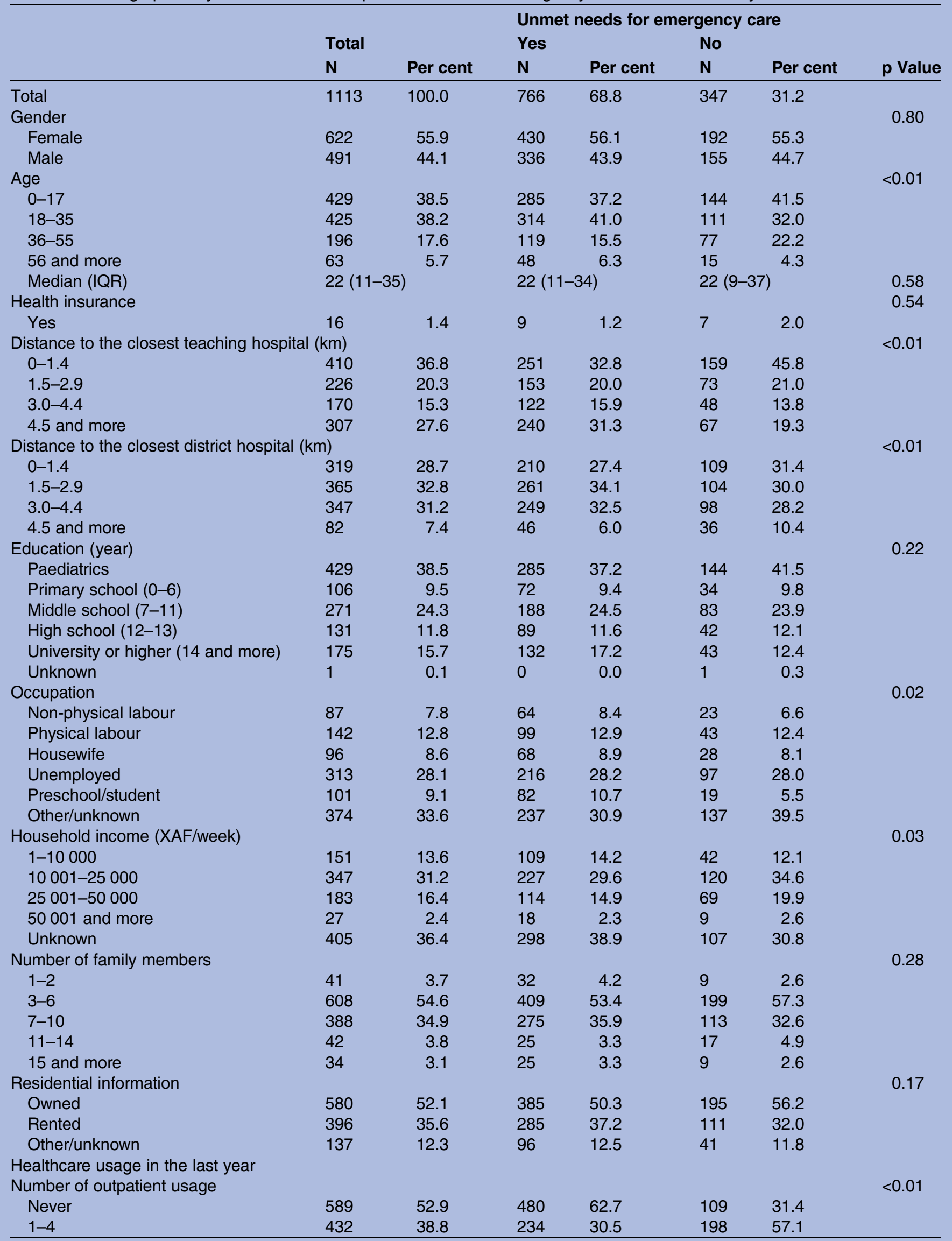


Table 2 Continued

\begin{tabular}{|c|c|c|c|c|c|c|c|}
\hline & & & Unn & eeds for $\mathrm{e}$ & genc & & \\
\hline & Total & & Yes & & No & & \\
\hline & $\mathbf{N}$ & Per cent & $\mathbf{N}$ & Per cent & $\mathbf{N}$ & Per cent & p Value \\
\hline $5-8$ & 55 & 4.9 & 33 & 4.3 & 22 & 6.3 & \\
\hline $9-12$ & 25 & 2.2 & 12 & 1.6 & 13 & 3.7 & \\
\hline 13 and more & 6 & 0.5 & 1 & 0.1 & 5 & 1.4 & \\
\hline Unknown & 6 & 0.5 & 6 & 0.8 & 0 & 0.0 & \\
\hline Number of emergency unit usage & & & & & & & $<0.01$ \\
\hline Never & 1032 & 92.7 & 737 & 96.2 & 295 & 85.0 & \\
\hline $1-4$ & 74 & 6.6 & 25 & 3.3 & 49 & 14.1 & \\
\hline $5-8$ & 4 & 0.4 & 2 & 0.3 & 2 & 0.6 & \\
\hline Unknown & 3 & 0.3 & 2 & 0.3 & 1 & 0.3 & \\
\hline Number of hospitalisation & & & & & & & $<0.01$ \\
\hline Never & 966 & 86.8 & 704 & 91.9 & 262 & 75.5 & \\
\hline $1-4$ & 141 & 12.7 & 58 & 7.6 & 83 & 23.9 & \\
\hline $5-8$ & 3 & 0.3 & 1 & 0.1 & 2 & 0.6 & \\
\hline Unknown & 3 & 0.3 & 3 & 0.4 & 0 & 0.0 & \\
\hline
\end{tabular}

should be reflected on policy development and assurance of access to an emergency care system for the Cameroonians.

In sub-Saharan Africa, there are growing evidences showing that a full-capacity emergency facility or access to basic emergency care is associated with a significant reduction in in-hospital mortality. ${ }^{1} 78$ However, total expenditure on health in Cameroon was only $5 \%$ of the GDP in the past 15 years, and emergency care system development is still in a nascent stage. ${ }^{12}{ }^{14}$ In this study, only $7.0 \%$ of respondents who experienced emergency conditions reported using emergency units, and the primary reason for not seeking healthcare was economic issue $(37.2 \%)$. Furthermore, low socioeconomic positions such as low household income and rental housing were associated with unmet needs for emergency care. Life-threatening illnesses or injuries put individuals and families in a position to choose between financial burdens of medical care and risks of death or lifelong disability for missing out on healthcare. In order to provide timely and appropriate healthcare services to all, access to emergency care should be assured despite socioeconomic inequalities. Moreover, financial protection plans should be provided to protect urgent or lifethreatening patients from high medical costs, which would ultimately improve usage of emergency care and enhance outcomes through universal emergency care. $^{1} 29$

Recent epidemiological studies suggest that the global burden of disease in LMIC is shifting away from infectious diseases towards time-sensitive illnesses and acute injuries such as ischaemic heart disease, cerebrovascular disease and unintentional injuries, which had been more commonly observed in higher income countries. $^{1-5} 1318$ In this study, neurological emergency, intoxication and cardiovascular emergency were more frequently observed than infectious emergency conditions. Furthermore, younger populations in LMIC visited emergency facilities with severe injuries and high levels of critical illnesses; ${ }^{19}$ median age of these populations with emergency conditions was 22 years. Currently, $45 \%$ of all deaths and $36 \%$ of disability-adjusted life-years in LMIC are caused by conditions amenable to secondary prevention, and therefore, strengthening of emergency care systems is essential to promote public health by providing appropriate care to time-sensitive diseases. ${ }^{1} 410$

Prehospital care is one of the essential components of emergency care for increasing accessibility to emergency care. ${ }^{4}$ Prehospital emergency care is rarely provided in LMIC including Cameroon, and the majority of critically ill patients and injury victims arrive at the hospital using a taxi or a private automobile. ${ }^{420}$ Since a delay in lifesaving procedures and lack of transportation could lead to avoidable mortality and morbidity, there is a significant need for transporting a patient from the location of an acute event incidence to a hospital by equipped ambulance and trained prehospital emergency care providers. $^{1} 2921$

Lack of trained emergency care professionals and equipped facilities has been identified as a major obstacle to emergency care delivery in LMIC. ${ }^{11} 16$ Previous studies reported that healthcare professionals in district hospitals had relatively poor skills for managing lifethreatening conditions due to lack of specific training in emergency care and poorly equipped facilities. ${ }^{16} 1921$ As emergency care personnel are essential human resources for providing emergency care, a well-designed education programme is needed to train emergency care professionals with well-rounded competence in the diagnosis and treatment of emergency patients; be able to manage patients; effectively use emergency resources; cooperate with local communities; and develop and collaborate with prehospital emergency care system. ${ }^{6}$

Use of self-medication, home care or traditional medicine was one of main reasons for not seeking healthcare and was especially high in patients with intoxication/ 
Table 3 Incidence of emergency conditions, unmet needs of emergency care and reasons for non-visits

\begin{tabular}{|c|c|c|c|c|c|c|c|c|c|}
\hline & \multirow[b]{2}{*}{$\begin{array}{l}\text { Persons with } \\
\text { any conditions } \\
\mathbf{N}\end{array}$} & \multirow[b]{2}{*}{$\begin{array}{l}\text { Persons with } \\
\text { any unmet } \\
\text { needs } \\
\mathrm{N}(\%)\end{array}$} & \multicolumn{7}{|c|}{ Reasons for non-visits of unmet needs } \\
\hline & & & $\begin{array}{l}\text { Economic } \\
\text { issue } \\
\mathbf{N}\end{array}$ & $\begin{array}{l}\text { Complementary } \\
\text { medicine } \\
\mathrm{N}\end{array}$ & $\begin{array}{l}\text { Not severe } \\
\text { enough to } \\
\text { visit } \\
\mathrm{N} \\
\end{array}$ & $\begin{array}{l}\text { Low } \\
\text { accessibility } \\
\mathrm{N}\end{array}$ & $\begin{array}{l}\text { Social } \\
\text { disapproval } \\
\mathbf{N}\end{array}$ & $\begin{array}{l}\text { Distrust in } \\
\text { hospital } \\
\text { care } \\
\mathrm{N} \\
\end{array}$ & $\begin{array}{l}\text { Others } \\
\mathbf{N}\end{array}$ \\
\hline \multicolumn{10}{|c|}{ Emergency conditions } \\
\hline Any emergency & 1113 & $766(68.8)$ & $285(37.2)$ & $170(22.2)$ & $67(8.7)$ & $44(5.7)$ & $35(4.6)$ & $9(1.2)$ & $176(23.0)$ \\
\hline $\begin{array}{l}\text { Neurological } \\
\text { emergency }\end{array}$ & 322 & $208(64.6)$ & $88(42.3)$ & $40(19.2)$ & $25(12.0)$ & $7(3.4)$ & $12(5.8)$ & $0(0.0)$ & $36(17.3)$ \\
\hline $\begin{array}{l}\text { Intoxication/ } \\
\text { metabolic disorder }\end{array}$ & 138 & $90(65.2)$ & $38(52.8)$ & $25(34.7)$ & $4(5.6)$ & $1(1.4)$ & $4(5.6)$ & $0(0.0)$ & $18(25.0)$ \\
\hline $\begin{array}{l}\text { Cardiovascular } \\
\text { emergency }\end{array}$ & 122 & $72(59.0)$ & $27(30.0)$ & $14(15.6)$ & $6(6.7)$ & $1(1.1)$ & $3(3.3)$ & $0(0.0)$ & $21(23.3)$ \\
\hline Infection & 112 & $74(66.1)$ & $15(20.3)$ & $19(25.7)$ & $7(9.5)$ & $1(1.4)$ & $2(2.7)$ & $1(1.4)$ & $29(39.2)$ \\
\hline $\begin{array}{l}\text { Paediatric } \\
\text { emergency }\end{array}$ & 77 & $40(51.9)$ & $15(37.5)$ & $10(25.0)$ & $1(2.5)$ & $4(10.0)$ & $1(2.5)$ & $1(2.5)$ & $8(20.0)$ \\
\hline Trauma & 72 & $32(44.4)$ & $14(43.8)$ & $1(3.1)$ & $8(25.0)$ & $0(0.0)$ & $0(0.0)$ & $0(0.0)$ & $9(28.1)$ \\
\hline $\begin{array}{l}\text { Surgical } \\
\text { emergency }\end{array}$ & 60 & $29(48.3)$ & $10(34.5)$ & $4(13.8)$ & $0(0.0)$ & $0(0.0)$ & $1(3.4)$ & $4(13.8)$ & $10(34.5)$ \\
\hline $\begin{array}{l}\text { Ophthalmology } \\
\text { emergency }\end{array}$ & 54 & $35(64.8)$ & $18(51.4)$ & $2(5.7)$ & $2(5.7)$ & $3(8.6)$ & $1(2.9)$ & $0(0.0)$ & $9(25.7)$ \\
\hline Allergies & 53 & $40(75.5)$ & $15(37.5)$ & $8(20.0)$ & $2(5.0)$ & 5 (12.5) & $5(12.5)$ & $0(0.0)$ & $5(12.5)$ \\
\hline $\begin{array}{l}\text { Obstetric } \\
\text { emergency }\end{array}$ & 51 & $19(37.3)$ & $12(63.2)$ & $1(5.3)$ & $0(0.0)$ & $0(0.0)$ & $3(15.8)$ & $0(0.0)$ & $3(15.8)$ \\
\hline Haemorrhage & 49 & $33(67.3)$ & $10(30.3)$ & $1(3.0)$ & $0(0.0)$ & $16(48.5)$ & $1(3.0)$ & $1(3.0)$ & $4(12.1)$ \\
\hline Foreign body & 27 & 9 (33.3) & $6(66.7)$ & $1(11.1)$ & $0(0.0)$ & $0(0.0)$ & $0(0.0)$ & $0(0.0)$ & $2(22.2)$ \\
\hline $\begin{array}{l}\text { Psychiatric } \\
\text { emergency }\end{array}$ & 9 & 8 (88.9) & $1(12.5)$ & $2(25.0)$ & $0(0.0)$ & $2(25.0)$ & $2(25.0)$ & $0(0.0)$ & $1(12.5)$ \\
\hline Other emergency & 215 & $169(78.6)$ & $48(28.4)$ & $54(32.0)$ & $14(8.3)$ & $4(2.4)$ & $2(1.2)$ & $2(1.2)$ & $45(26.6)$ \\
\hline
\end{tabular}


Table 4 Multivariable logistic analysis for unmet needs of emergency care among respondents who had emergency conditions in the last year

\begin{tabular}{|c|c|c|}
\hline & $\begin{array}{l}\text { Unadjusted } \\
\text { OR }(95 \% \mathrm{CI})\end{array}$ & $\begin{array}{l}\text { Adjusted } \\
\text { OR }(95 \% \mathrm{Cl})\end{array}$ \\
\hline \multicolumn{3}{|l|}{ Gender } \\
\hline Female & $1.03(0.80$ to 1.33$)$ & $1.00(0.77$ to 1.32$)$ \\
\hline Male & 1.00 & 1.00 \\
\hline \multicolumn{3}{|l|}{ Age } \\
\hline $0-17$ & $1.28(0.90$ to 1.82$)$ & $1.28(0.89$ to 1.85$)$ \\
\hline $18-35$ & $1.83(1.28$ to 2.62$)$ & $1.80(1.23$ to 2.62$)$ \\
\hline $36-55$ & 1.00 & 1.00 \\
\hline 56 and more & 2.07 (1.08 to 3.95$)$ & 2.08 (1.06 to 4.09$)$ \\
\hline \multicolumn{3}{|c|}{ Distance to the closest teaching hospital (km) } \\
\hline $0-1.4$ & 1.00 & 1.00 \\
\hline $1.5-2.9$ & $1.33(0.94$ to 1.87$)$ & 1.40 (0.97 to 2.02$)$ \\
\hline $3.0-4.4$ & 1.61 (1.09 to 2.38$)$ & 2.78 (1.77 to 4.35$)$ \\
\hline 4.5 and more & $2.27(1.62$ to 3.18$)$ & 5.39 (3.41 to 8.53$)$ \\
\hline \multicolumn{3}{|c|}{ Distance to the closest district hospital $(\mathrm{km})$} \\
\hline $0-1.4$ & 1.51 (0.92 to 2.47$)$ & 6.90 (3.57 to 13.34$)$ \\
\hline $1.5-2.9$ & 1.96 (1.20 to 3.21$)$ & 6.99 (3.76 to 13.01$)$ \\
\hline $3.0-4.4$ & $1.99(1.21$ to 3.26$)$ & 4.00 (2.30 to 6.97$)$ \\
\hline 4.5 and more & 1.00 & 1.00 \\
\hline \multicolumn{3}{|c|}{ Household income (XAF/week) } \\
\hline $1-10000$ & 1.00 & 1.00 \\
\hline $10001-25000$ & $0.73(0.48$ to 1.11$)$ & $0.78(0.50$ to 1.24$)$ \\
\hline $25001-50000$ & $0.64(0.40$ to 1.01$)$ & $0.60(0.36$ to 0.99$)$ \\
\hline $\begin{array}{l}50001 \text { and } \\
\text { more }\end{array}$ & 0.77 (0.32 to 1.85$)$ & 0.97 (0.39 to 2.46$)$ \\
\hline Unknown & $1.07(0.71$ to 1.63$)$ & $1.51(0.95$ to 2.40$)$ \\
\hline \multicolumn{3}{|c|}{ Residential information } \\
\hline Owned & 1.00 & 1.00 \\
\hline Rented & $1.30(0.98$ to 1.72$)$ & 1.50 (1.11 to 2.03$)$ \\
\hline $\begin{array}{l}\text { Other/ } \\
\text { unknown }\end{array}$ & 1.19 (0.79 to 1.78$)$ & 1.47 (0.93 to 2.31$)$ \\
\hline
\end{tabular}

metabolic disorder. Enhancement of usage of emergency care services by providing a universal high quality of emergency care and reducing the barriers to visit healthcare facilities could decrease the self-treatment without diagnosis and prescriptions by emergency care professionals.

An emergency care system is a critical component of the national health systems in LMIC. $^{9}$ An emergency care system needs to be well planned and supported throughout the continuum of care, from the occurrence of an acute medical event in a community to the provision of appropriate care at a destination hospital. ${ }^{21}$ The Yaoundé National Emergency Center (Centre des Urgences de Yaoundé) opened in 2015 that could be one of cornerstones to provide universal emergency care to Cameroonians. In 2017, specialised training programmes for emergency care physicians and prehospital emergency care providers will be developed and implemented. We have been planning a follow-up study to evaluate the demands, usage and unmet needs for emergency care in 2017 and reassess them every 2 years in Yaoundé, Cameroon. Comprehensive assessment and continuous monitoring of demands, usage and unmet needs for emergency care would assist development of an evidence-based, effective emergency care system and health policies that incorporate Cameroonians' needs.

\section{Limitations}

There are several limitations in this study. First, we used two-stage sampling methods to obtain a representative sample of residents in Yaoundé, Cameroon. The response rate $(92.8 \%)$ was relatively high; however, these issues could have led to selection bias. Furthermore, the civil registration of births only covered $61 \%$ of all Cameroonians, ${ }^{13}$ and information about the number of households in each community was not available. We did not calculate sampling weights and could not estimate prevalence of unmet needs for the whole target population. Second, we used face-to-face interview methods to survey demands, usage or unmet needs for emergency care. There is a possibility of misclassification by the respondents or interviewers and/or disagreement between interviewers for the categorisation of emergency conditions or reasons for not seeking healthcare, although a mandatory 2-day surveyor training programme and data quality control protocol were put in place. Third, the emergency condition and demands of emergency care were described with broad definitions and based on subjective judgements that involved the risk of summarising a variety of conditions and healthcare needs which might cause misclassification. Fourth, we used the classification of emergency conditions focusing to describe the scope of emergencies that impairs the differentiation of the severity and urgency of emergency conditions and the necessary healthcare resources. Fifth, survey responders answered for all household members for the previous year's emergency condition, which might cause memory bias. Sixth, resources and systems of emergency care services would differ by sociocultural context and limits generalisability of the study.

\section{CONCLUSIONS}

There was a high burden of emergency conditions, illnesses and acute injuries observed in Yaoundé, Cameroon. However, usage of emergency care was uncommon, and unmet needs for emergency care were very high. An overall improvement in accessibility to an emergency care system, affordability and a reasonable payment system for emergency care, efforts to train highly skilled personnel and enhanced life-saving capability may contribute to increased usage of the emergency care system and enhance public health.

\section{Author affiliations}

${ }^{1}$ Laboratory of Emergency Medical Services, Seoul National University Hospital Biomedical Research Institute, Seoul, Korea

${ }^{2}$ Department of Emergency Medicine, Seoul National University College of Medicine, Seoul, Korea 
${ }^{3}$ Korea International Cooperation Agency, Korea

${ }^{4}$ Department of Emergency Medicine, Centre des Urgences de Yaoundé Yaoundé, Cameroon

${ }^{5}$ Faculty of Medicine and Biomedical Services, Department of Epidemiology, University of Yaoundé, Yaoundé, Cameroon

${ }^{6}$ Department of Disease Control, Epidemics and Pandemics, Ministry of Public Health, Cameroon

${ }^{7}$ Department of Emergency Medicine, Centre des Urgences de Yaoundé, Yaoundé, Cameroon

Contributors YSR and SDS had full access to all of the data in the study and take responsibility for the integrity of the data and the accuracy of the data analysis. YSR, SDS and JJ were involved in study concept and design. MJK, $\mathrm{YHJ}$ and $\mathrm{BH}$ were involved in acquisition, analysis or interpretation of data. YSR and MJK were involved in drafting of the manuscript. SDS, JJ, JK and EMGA were involved in critical revision of the manuscript for important intellectual content. YSR and SDS were involved in statistical analysis. SDS and $\mathrm{JJ}$ obtained funding. MJK and BH were involved in administrative, technical or material support. SDS, JJ, JK and EMGA were involved in study supervision. All authors were involved in manuscript approval.

Funding This study was financially supported by the Korea International Cooperation Agency (KOICA).

Competing interests None declared.

Patient consent Obtained.

Ethics approval The Institutional Review Board (IRB) of the Seoul National University Hospital (IRB No. 1408-015-600) and the National Ethics Committee of Cameroon (IRB No. 2014/10/503/CE/CNERSH/SP).

Provenance and peer review Not commissioned; externally peer reviewed.

Data sharing statement No additional data are available.

Open Access This is an Open Access article distributed in accordance with the Creative Commons Attribution Non Commercial (CC BY-NC 4.0) license, which permits others to distribute, remix, adapt, build upon this work noncommercially, and license their derivative works on different terms, provided the original work is properly cited and the use is non-commercial. See: http:// creativecommons.org/licenses/by-nc/4.0/

\section{REFERENCES}

1. Razzak JA, Kellermann AL. Emergency medical care in developing countries: is it worthwhile? Bull World Health Organ 2002;80:900-5.

2. Levine AC, Presser DZ, Rosborough S, et al. Understanding barriers to emergency care in low-income countries: view from the front line. Prehosp Disaster Med 2007;22:467-70.

3. Hofman K, Primack A, Keusch G, et al. Addressing the growing burden of trauma and injury in low- and middle-income countries. Am J Public Health 2005;95:13-17.
4. Anderson PD, Suter RE, Mulligan T, et al. World Health Assembly Resolution 60.22 and its importance as a health care policy tool for improving emergency care access and availability globally. Ann Emerg Med 2012;60:35-44. e3.

5. Dalal S, Beunza JJ, Volmink J, et al. Non-communicable diseases in sub-Saharan Africa: what we know now. Int J Epidemiol 2011;40:885-901.

6. Reynolds TA, Mfinanga JA, Sawe HR, et al. Emergency care capacity in Africa: a clinical and educational initiative in Tanzania. $J$ Public Health Policy 2012;33(Suppl 1):S126-37.

7. Sawe HR, Mfinanga JA, Mwafongo V, et al. Trends in mortality associated with opening of a full-capacity public emergency department at the main tertiary-level hospital in Tanzania. Int J Emerg Med 2015;8:24.

8. Fournier $\mathrm{P}$, Dumont $\mathrm{A}$, Tourigny $\mathrm{C}$, et al. Improved access to comprehensive emergency obstetric care and its effect on institutional maternal mortality in rural Mali. Bull World Health Organ 2009;87:30-8.

9. Kobusingye OC, Hyder AA, Bishai D, et al. Emergency medica systems in low- and middle-income countries: recommendations for action. Bull World Health Organ 2005;83:626-31.

10. The Core Curriculum and Education Committee for the International Federation for Emergency Medicine. International Federation for Emergency Medicine model curriculum for emergency medicine specialists. CJEM 2011;13:109-21.

11. Hsia RY, Mbembati NA, Macfarlane S, et al. Access to emergency and surgical care in sub-Saharan Africa: the infrastructure gap. Health Policy Plan 2012;27:234-44.

12. World Bank Open Data-Cameroon: The World Bank; 2015. http:// data.worldbank.org/country/cameroon

13. World Bank. World health statistics 2015. Geneva, Switzerland: World Health Organization, 2015.

14. The World Factbook: Cameroon: Central Intelligence Agency; 2015. https://www.cia.gov/library/publications/the-world-factbook/geos/cm. html.

15. Juillard C, Etoundi Mballa GA, Bilounga Ndongo C, et al. Patterns of injury and violence in Yaoundé Cameroon: an analysis of hospital data. World J Surg 2011;35:1-8.

16. Chichom-Mefire A, Mbarga-Essim NT, Monono ME, et al. Compliance of district hospitals in the Center Region of Cameroon with WHO/IATSIC guidelines for the care of the injured: a cross-sectional analysis. World J Surg 2014;38:2525-33.

17. Keja K, Chan C, Hayden G, et al. Expanded programme on immunization. World Health Stat Q 1988;41:59-63.

18. Chichom Mefire A, Etoundi Mballa GA, Azabji Kenfack M, et al Hospital-based injury data from level III institution in Cameroon: retrospective analysis of the present registration system. Injury 2013:44:139-43.

19. Obermeyer Z, Abujaber S, Makar M, et al. Emergency care in 59 low- and middle-income countries: a systematic review. Bull World Health Organ 2015;93:577-86G.

20. McGreevy J, Stevens KA, Ekeke Monono M, et al. Road traffic injuries in Yaoundé, Cameroon: a hospital-based pilot surveillance study. Injury 2014;45:1687-92.

21. Razzak JA, Hyder AA, Akhtar T, et al. Assessing emergency medical care in low income countries: a pilot study from Pakistan. BMC Emerg Med 2008;8:8. 